\title{
Biomarkers, imaging and disease activity indices in patients with early axial spondyloarthritis: the Italian arm of the SpondyloArthritis-Caught-Early (SPACE) Study
}

\author{
M. Lorenzin'1, A. Ortolan1, S. Vio², M. Favero', F. Oliviero', M. Zaninotto, \\ C. Cosma ${ }^{3}$, C. Lacognata ${ }^{2}$, L. Punzi ${ }^{1}$, R. Ramonda ${ }^{1}$ \\ ${ }^{1}$ Rheumatology Unit, Department of Medicine - DIMED, University of Padova, Italy; ${ }^{2}$ Radiology Unit, \\ University of Padova, Italy; ${ }^{M}$ Medicine of Laboratory, University of Padova, Italy
}

\begin{abstract}
The study aimed to evaluate biomarkers facilitating early diagnosis of axial spondyloarthritis (axSpA) and correlations between them and disease activity parameters and imaging indexes.

Patients with low back pain (LBP) ( $\geq 3$ months, $\leq 2$ years, onset $\leq 45$ years) participating in the Italian arm of the SpondyloArthritis-Caught-Early SPACE study underwent a physical examination, questionnaires, laboratory tests, X-rays and MRI of the spine and sacroiliac joints (SIJ). An expert rheumatologist formulated axSpA diagnosis in accordance with Assessment of SpondyloArthritis International Society (ASAS) criteria. Disease activity and physical functioning were assessed using imaging, clinical and serological indices. Spine and SIJ MRI and X-rays were scored independently by 2 readers using the SPARCC, mSASSS and NY-criteria. Patients were classified as: subjects with signs of radiographic sacroiliitis (r-axSpA), subjects with signs of sacroiliitis on SIJ-MRI but not on X-rays (nr-axSpA MRI SIJ+) or subjects with no signs of sacroiliitis on MRI/X-rays but with $>2$ SpA features and signs of bone oedema on MRI spine (nr-axSpA MRI SIJ-/undifferentiated SpA). Significant differences were found in the prevalence of radiographic sacroiliitis, active sacroiliitis on MRI and SPARCC SIJ scores. Biomarker levels were not significantly increased in any of the patient groups. The correlations between IL-17 and IL-23 and other indices were not significant; correlations were found between IL-22 and BASFI, BASG1, HAQ, VAS pain, between mSASSS and MMP3, and between the latter and hsCRP. Although not significantly higher in any of the three groups, IL-22, MMP3 and hsCRP values were correlated with some disease activity indexes and with mSASSS. Large observational studies are required to confirm these preliminary findings.
\end{abstract}

SUMMARY

Key words: Spondyloarthritis; low back pain; early axSpA; biomarkers; disease activity; bone oedema lesions on MRI.

Reumatismo, 2017; 69 (2): 65-74

\section{INTRODUCTION}

A xial spondyloarthritis (axSpA) is an umbrella term defining an early age onset chronic inflammatory disease, which, if undiagnosed and untreated, can result in permanent damage and lifelong disability $(1,2)$. AxSpA defines the entire spectrum of axial skeleton involvement spanning from ankylosing spondylitis (AS) to forms that have not yet or may never develop radiographic sacroiliitis, which fall under the category of non-radiographic axSpA (nr-axSpA) and which are often associated with bone oedema signs on spine magnetic resonance imaging (MRI) (3). The term radiographic axSpA (r-axSpA) is used instead for AS by studies whose selection criteria were based on the Assessment of SpondyloArthritis International Society (ASAS) one (1). These classification criteria seem to be able to identify patients with early stages of suspected axSpA. In fact, as far
Indirizzo per la corrispondenza: Roberta Ramonda University of Padova Via Giustiniani, 2 - 35128 Padova, Italy E-mail: roberta.ramonda@unipd.it 
as imaging data are concerned, they include the presence of sacroiliitis on MRI or X-rays in addition to one $\mathrm{SpA}$ feature for patients with onset of chronic low back pain (LBP) at or before 45 years. Conventional radiographs of sacroiliac joints (SIJ) (4), which are frequently used to detect sacroiliitis, do not appear to provide adequate information to formulate an early diagnosis $(1,4)$. MRI can, instead, detect inflammatory lesions of SIJ in patients with early-onset axSpA without radiographic evidence of sacroiliitis $(5,6)$. Recently, several studies have focused on biomarkers that could facilitate early diagnosis and identify individuals at higher risk of developing the disease (7-9). Tumor necrosis factor $\alpha$ $(\mathrm{TNF} \alpha)$ is a crucial cytokine that plays an essential role during the inflammatory response in SpA (10). According to recent findings, the (IL)-23/IL-17 immune axis also appears to play an important role in its pathogenesis (11-15). Several investigators have begun to examine serum and plasma biomarkers to assess their association with disease activity (DA) $(16,17)$, since erythrocyte sedimentation rate (ESR) and C-reactive protein (CRP), commonly considered acute-phase proteins reflecting systemic inflammation, often prove to be unrelated to inflammation in axSpA (18-20). Higher CRP levels in patients with $\mathrm{r}-\mathrm{axSpA}$ with respect to their nr-axSpA peers $(21,22)$ have been described. Although CRP is not elevated in a large percentage of patients with active axSpA, it is widely considered a reliable parameter of DA and is correlated with the Ankylosing Spondylitis disease activity score (ASDAS) and the Bath Ankylosing Spondylitis Disease Activity Index (BASDAI). As CRP is moderately correlated with MRI signs of inflammation, it can be considered an efficacious tool for assessing DA and treatment response and for predicting further structural disease progression $(16,17,20,21)$. Baseline CRP levels represent a strong predictor of radiographic structural damage progression, and, in particular, of the transition from nr-axSpA to AS (20,
21, 23). Recent studies have focused on the role of other biomarkers to diagnose early-stage axSpA, to evaluate DA, and to predict patients at higher risk of worse outcome $(16,17)$. Among these, matrix metalloproteinase (MMP) markers (and, in particular, MMP3) have also been considered possible biomarkers of DA given the correlation between MMP3 and CRP, DA and functional indices, such as BASDAI and Bath Ankylosing Spondylitis Functional Index (BASFI) (17, 24-26), and of the radiographic progression in AS patients (27). Although serum MMP3 represents a reliable parameter of DA, there is often no correlation with inflammatory MRI findings (26). The aim of the current study was to examine some serological biomarkers, clinical and imaging parameters and DA indices in patients with early axSpA who were participating in the Italian arm of the SpondyloArthritis Caught Early (SPACE) study.

\section{MATERIALS AND METHODS}

\section{Patients}

Patients who were at least 16 years old, suffering with inflammatory low back pain (LBP) ( $\geq 3$ months, $\leq 2$ years, onset $<45$ years) of unknown origin and referred to a rheumatologist were included in the Italian arm of the SPACE study which is an on-going observational cohort study that was originally launched at the Leiden University Medical Centre (LUMC, Holland) in January 2009, in collaboration with Rheumatology Unit of the University of Padua Medical Center (Italy) since March 2012. Patients qualifying for the study, in accordance with the ASAS criteria (1), were assessed following a specific protocol including physical examination, laboratory tests, SIJ/spine plain radiographs and MRI, questionnaires' regarding DA and functional state. The SpA features considered for diagnosis in accordance with the ASAS criteria (1) were radiographic sacroiliitis (modified New York $=\mathrm{mNY}$ criteria $=$ bilateral grade $\geq 2$ or unilateral grade $\geq 3$ ), sacroiliitis on MRI (presence of $\geq 2$ inflammatory 
lesions highly suggestive of axSpA on a single slice or one lesion on $\geq 2$ consecutive slices), Human Leukocyte Antigen HLA-B27 positivity, positive family history for SpA, inflammatory (I)BP, psoriasis, peripheral arthritis, dactylitis, heel enthesitis, uveitis, inflammatory bowel disease (IBD), good response to non-steroidal anti-inflammatory drugs (NSAIDs) and elevated CRP or ESR. Only patients diagnosed with axSpA by two expert rheumatologists (RR and ML) were considered eligible for the study. All clinical, imaging, DA and serological indices considered were assessed at baseline, a time during which all the patients were being treated with only NSAIDs and not with conventional synthetic disease-modifying anti-rheumatic drugs (csDMARDs) or biologics. The study design was approved by the local ethics committee in accordance with the principles of the Declaration of Helsinki; informed consent was obtained from all of the eligible participants. The patients' X-rays and MRI images were scored independently by two expert readers ( $\mathrm{SV}$ and $\mathrm{LC}$ ), and the patients were classified, in accordance with the ASAS criteria for axSpA (1), into three patient cohorts: those fulfilling the $\mathrm{mNY}$ criteria for radiographic sacroiliitis ( $\mathrm{r}-\mathrm{axSpA})$, those without signs of radiographic sacroiliitis but with signs of active sacroiliitis on MRI (nr-axSpA MRI SIJ+), those with positive HLA-B27 and with $\geq 2$ additional SpA features but without signs of sacroiliitis on MRI or plain radiographs or those with $\geq 2$ additional SpA features, negative HLA B27 and signs of BME on spine MRI (in accordance with ASAS/OMERACT criteria) (28) - (nr-axSpA MRI SIJ-/uSpA). Patients with suspected axSpA who did not fulfill the ASAS criteria and did not present any bone oedema signs on spine and pelvis MRI were excluded. The protocol for acquiring the MRI and plain radiograph images and for classifying clinical and clinimetric indexes (Bath Ankylosing Spondylitis Metrology Index (BASMI) and Maastricht Ankylosing enthesitis Spondilities Score (MASES), functional indices of disease activity BASDAI, BASFI; Visual Analogue Scale (VAS pain); VAS night pain, disease activity VAS; Bath Ankylosing Spondylitis Patient Global Score (BASG1); BASG2; Health Assessment Questionnaire (HAQ); Ankylosing Spondylitis disease activity score (ASDAS)) have been described elsewhere by Lorenzin et al. (29). As explained, the MRI images were analyzed in accordance with the ASAS/EULAR criteria $(5,6)$ and the Spondyloarthritis Research Consortium of Canada (SPARCC) score (30, 31 , while spine X-Rays and SIJ X-Rays were scored in accordance with the Stoke Ankylosing Spondylitis Spinal Score (SASSS) system modified by Creemers (mSASSS) (32) and the NY criteria (4).

\section{Serological evaluation}

ESR [normal range $0-15 \mathrm{~mm} / \mathrm{h}$ ] and CRP [normal range 0-6 mg/L] values were determined. Serum ultrasensitive CRP (hsCRP), (Research \& Diagnostic Systems, Inc., expressed in $\mathrm{mg} / \mathrm{L}$, with a lower limit of detection of $0 \mathrm{mg} / \mathrm{L}$ ); MMP3, (Quantikine MMP3 R\&D Systems Europe, expressed in $\mathrm{ng} / \mathrm{mL}$, with a lower limit of detection of $0 \mathrm{ng} / \mathrm{mL}$ ); IL-22, IL-17 and IL-23 (R\&D Systems Europe, expressed in $\mathrm{pg} / \mathrm{mL}$, with lower limit of detection respectively of $5 \mathrm{pg} / \mathrm{mL}, 17 \mathrm{pg} / \mathrm{mL}$, of 20 $\mathrm{pg} / \mathrm{mL}$ ) were assessed using an enzymelinked immunosorbent assay (ELISA). Serum for the assays was separated by centrifugation at $3000 \mathrm{rpm}$ for $10 \mathrm{~min}$ and stored at $-80^{\circ} \mathrm{C}$. All blood samples were analyzed twice using the same method.

\section{Statistical analyses}

The Kruskal Wallis test (ANOVA) was used to compare the following indices: clinical (BASMI, MASES), serological (ESR, CRP, hs-CRP, MMP3, IL-22, IL-17, IL-23), functional (BASFI, HAQ, BASG1, BASG2, VAS pain, VAS night pain, disease activity VAS), DA (BASDAI, ASDAS) indices and imaging scores (mSASSS, NY score, SPARCC SIJ and SPARCC 6-DVU) at baseline in the three cohorts $(\mathrm{r}-\mathrm{axSpA}$, nr-axSpA MRI SIJ+ and nr-axSpA MRI SIJ-). The Spearman test was used to ana- 
lyze the correlation between clinical, serological, DA and imaging score indices. A $\mathrm{p}$ value $<0.05$ was considered significant.

\section{RESULTS}

All 60 patients enrolled in the study fulfilled the ASAS criteria for axSpA; $23(38.3 \%)$ were diagnosed with r-axSpA, $17(28.3 \%)$ with nr-axSpA MRI SIJ+ and 20 (33.3\%) with nr-axSpA MRI SIJ-/uSpA. The mean age at LBP onset was $29.05 \pm 8.38$ years, $27(45 \%)$ of the patients were male, 23 $(38.3 \%)$ were HLA-B27+. Axial involvement was noted in $33(55.7 \%)$ and axial/peripheral involvement in 27 (44.3\%). A detailed description of patients' clinical characteristics including the $\mathrm{SpA}$ features of the Italian SPACE cohort studied has been published elsewhere (29). Patients' clinical

Table I - Serological, clinical, DA and imaging score indices at baseline in the whole group of patients $(n=60)$ and in its three cohorts (r-axSpA, nr-axSpA MRI SIJ+, nr-axSpA MRI SIJ-/USpA).

\begin{tabular}{|c|c|c|c|c|c|}
\hline $\begin{array}{l}\text { Serological, clinical, DA } \\
\text { and imaging score indices }\end{array}$ & $\begin{array}{l}\text { Cohort } 1 \\
\text { r-axSpA, } n=23\end{array}$ & $\begin{array}{c}\text { Cohort } 2 \\
\text { nr-axSpA } \\
\text { MRI SIJ+, } n=17\end{array}$ & $\begin{array}{c}\text { Cohort } 3 \\
\text { nr-axSpA } \\
\text { MRI SIJ-/uSpA, n=20 }\end{array}$ & $p^{\S}$ & Total $=60 \mathrm{pts}$ \\
\hline $\mathrm{ESR}(\mathrm{mm} / \mathrm{h})$, mean $(\mathrm{SD})$ & $17.57(14.45)$ & $18.41(12.75)$ & $18.95(21.83)$ & ns & $18.27(16.61)$ \\
\hline CRP (mg/L), mean (SD) & $3.87(4.18)$ & $3.65(2.32)$ & $3.65(3.12)$ & ns & $3.73(3.33)$ \\
\hline hs-CRP (mg/L), mean (SD) & $2.54(2.79)$ & $1.56(1.71)$ & $2.76(3.76)$ & ns & $2.11(2.50)$ \\
\hline MMP3 (ng/L), mean (SD) & $3.04(2.69)$ & $3.51(3.12)$ & $2.47(2.68)$ & ns & $3.01(2.80)$ \\
\hline IL-22 (pg/mL), mean (SD) & $6.44(3.52)$ & $5.91(2.45)$ & $9.83(8.54)$ & ns & $12.58(11.69)$ \\
\hline IL-17 (pg/mL), mean (SD) & $3(3.12)$ & $3(3.11)$ & $3(3.97)$ & ns & $3(4.11)$ \\
\hline IL-23 (pg/mL), mean (SD) & $29.3(31.2)$ & $21.87(5.21)$ & $20.69(21.56)$ & ns & $71.53(60.56)$ \\
\hline HLA B27, n (\%) & $11(47.8)$ & $9(52.9 \%)$ & $3(15 \%)$ & ns & $23(38.3)$ \\
\hline BASMI, mean (SD) & $0.74(1.01)$ & $1.06(1.35)$ & $0.75(0.97)$ & ns & $1.83(1.09)$ \\
\hline MASES, mean (SD) & $2.87(2.39)$ & $4.35(2.69)$ & $3.6(2.37)$ & ns & $3.51(2.51)$ \\
\hline BASFI, mean (SD) & $16.22(23.96)$ & $24.74(23.19)$ & $15(15.73)$ & ns & $18.23(21.37)$ \\
\hline $\mathrm{HAQ}$, mean (SD) & $0.32(0.52)$ & $0.48(0.61)$ & $0.38(0.35)$ & ns & $0.38(0.49)$ \\
\hline BASG1, mean (SD) & $3.26(2.93)$ & $4.24(2.73)$ & $3.85(3.36)$ & ns & $3.73(3.01)$ \\
\hline BASG2, mean (SD) & $4.78(2.78)$ & $5.47(2.79)$ & $5.05(2.98)$ & ns & $5.07(2.82)$ \\
\hline VAS pain, mean (SD) & $3.70(3.01)$ & $4.06(3.07)$ & $4.55(3.27)$ & ns & $4.08(3.08)$ \\
\hline VAS disease activity, mean (SD) & $3.39(2.86)$ & $4.36(3.30)$ & $4.5(3.55)$ & ns & $4.03(3.21)$ \\
\hline VAS pain night, mean (SD) & $3.61(3.63)$ & $3.71(3.57)$ & $3.8(3.44)$ & ns & $3.07(3.49)$ \\
\hline BASDAI, mean (SD) & $38.02(25.58)$ & $53(25.61)$ & $46.38(23.75)$ & ns & $45.05(25.33)$ \\
\hline ASDAS, mean (SD) & $2.45(0.79)$ & $2.7(0.86)$ & $2.50(0.87)$ & ns & $2.53(0.81)$ \\
\hline Sacroiliitis $x$-ray ${ }^{\star *}, \mathrm{n}(\%)$ & $23(100 \%)$ & $0(0)$ & $0(0)$ & $<0.001$ & $25(41.7)$ \\
\hline Sacroilititis MRI ${ }^{\star}, \mathrm{n}(\%)$ & $17(73.9 \%)$ & $17(100 \%)$ & $0(0)$ & $<0.001$ & $32(53.3)$ \\
\hline mSASSS, mean (SD) & $3.26(3.21)$ & $3.53(4.86)$ & $3(3.73)$ & ns & $3.25(3.84)$ \\
\hline score SIJ, mean (SD) & $1.30(0.63)$ & $0(0)$ & $0(0)$ & ns & $0.5(0.75)$ \\
\hline SPARCC spine, mean (SD) & $7.26(12.33)$ & $5.18(15.52)$ & $2.05(3.49)$ & ns & $4.93(11.44)$ \\
\hline SPARCC SIJ, mean (SD) & $15.35(16.57)$ & $12.53(9.15)$ & $0(0)$ & $<0.001$ & $9.43(13.10)$ \\
\hline
\end{tabular}

ESR, erytrocyte sedimentation rate; CRP, C-reactive protein; hs-CRP, high sensitive C-reactive protein; MMP3, matrix-metalloproteinase 3; IL, interleukine; HLA-B27, Human Leukocyte Antigen; BASMI, Bath Ankylosing Score Metrology Index; MASES, Maastricht Ankylosing Spondilities Enthesitis Score; BASFI, Bath Ankylosing Spondylitis Functional Index; HAQ, Health Assessment Questionnaire; BASG1, Bath Ankylosing Spondylitis Patient Global Score 1; BASG2, Bath Ankylosing Spondylitis Patient Global Score 2; BASDAI, Bath Ankylosing Spondylitis Disease Activity Index; VAS, Visual Analogue Scale; ASDAS, Ankylosing Spondylitis Disease Activity Score; SPARCC, Spondyloarthritis Research Consortium of Canada; mSASSS, modified StokeAnkylosingSpondylitis Spine Score; SIJ, sacroiliac joints.

*Sacroiilitis MRI according ASAS/EULAR; **Sacroiliitis x-ray according New York criteria; $p \S$ Anova (Kruskal Wallis) a t0: $p<0.05$. 
and DA indices, biomarkers and imaging scores at baseline are outlined in Table I. There were significant differences, according to the Kruskal Wallis (ANOVA) test, in the cohorts as far as the prevalence of radiographic sacroiliitis, active sacroiliitis on MRI and the SPARCC SIJ scores was concerned (Table I). There were no differences in the serological markers (ILs, MMP3 and hsCRP) at baseline in the three groups. The ILs remained below detection levels in all of the cohorts. As expected, significant correlations were found between some clinical indices (BASFI, BASG1, BASG2, VAS) and between clinical and DA indices (BASDAI, ASDAS) (data not shown). The correlations between the clinical indices, MMP-3 and IL-22 are outlined in Table II; Table III highlights the correlations between ESR, hsCRP, and clinical indices. The most significant are outlined in Figure $1 \mathrm{~A}-\mathrm{F}$.

\section{DISCUSSION}

Unlike other inflammatory arthropathies, in particular rheumatoid arthritis, no single biomarker has been reproducibly
Table II - Correlations between MMP3, IL-22 and clinical indices.

\begin{tabular}{|l|c|c|}
\hline & MMP3 & IL-22 \\
\hline ESR & 0.047 & ns \\
\hline hsCRP & 0.026 & ns \\
\hline mSASSS & 0.005 & ns \\
\hline SPARCC & ns & 0.046 \\
\hline BASMI & ns & 0.038 \\
\hline BASFI & ns & 0.008 \\
\hline BASG1 & ns & 0.008 \\
\hline HAQ & ns & 0.041 \\
\hline MMP3 & ns & 0.017 \\
\hline
\end{tabular}

$P$ was calculated according Spearman's correlation test. The coefficient is positive unless otherwise stated

Table III - The most relevant correlations found between humoral and clinical indices.

\begin{tabular}{|l|c|c|}
\hline & hsCRP & ESR \\
\hline BASG1 & ns & 0.027 \\
\hline BASG2 & ns & 0.044 \\
\hline ASDAS & ns & 0.025 \\
\hline SPARCC SI & 0.043 & ns \\
\hline mSASSS & ns & 0.033 \\
\hline
\end{tabular}

$\mathrm{P}$ was calculated according Spearman's correlation test. The coefficient is positive unless otherwise stated

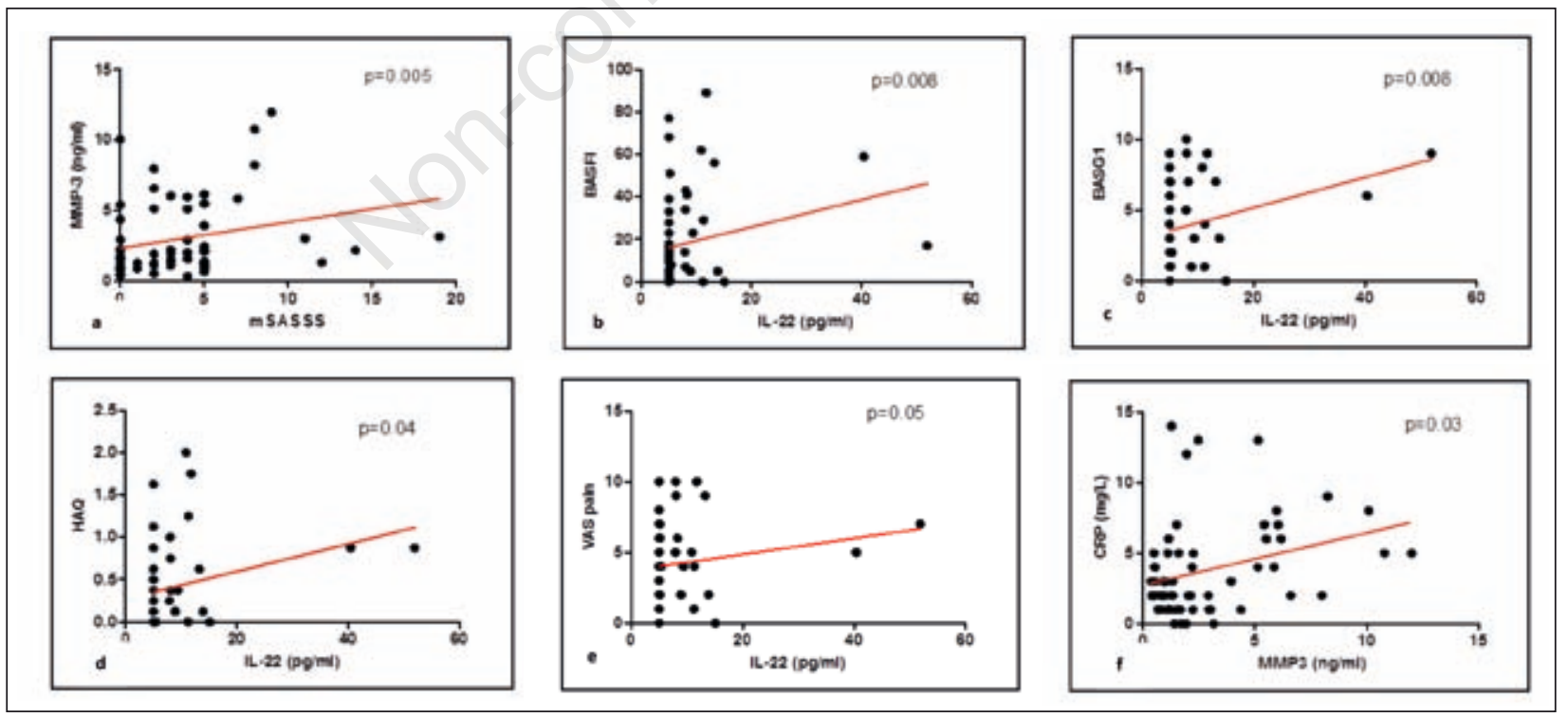

Figure 1 - Correlations between serological, clinical and disease activity indices in patients with early axSpA at baseline according to the Spearman correlation test $(\mathrm{p}<0.05)$. A) mSASSS and MMP3; B) IL-22 and BASFI; C) IL-22 and BASG1; D) IL-22 and HAQ; E) IL-22 and VAS pain; F) MMP3 and CRP. ESR, erytrocyte sedimentation rate; CRP, C-reactive protein; MMP3, matrix-metallo-proteinase 3; IL, interleukine; BASFI, Bath Ankylosing Spondylitis Functional Index; HAQ, Health Assessment Questionnaire; BASG1, Bath Ankylosing Spondylitis Patient Global Score 1; VAS, Visual Analogue Scale. 
shown to assess DA or to predict outcome in axSpA. DA assessment and monitoring has for the most part been limited to patients' self-reports that do not necessarily correlate with MRI-detected inflammation or CRP levels. TNF $\alpha$ is a crucial cytokine that plays an essential role during the inflammatory response in SpA (10) via the up-regulation of adhesive molecules, lymphocyte activation, fibroblast proliferation and the production of the main pro-inflammatory cytokines. TNF $\alpha$ levels are significantly higher in AS patients with respect to subjects with non-inflammatory back pain or healthy controls (10). Although it is not a reliable biomarker of DA, TNF- $\alpha$ assessment is considered a step forward in axSpA management that has significantly improved patient outcome (33). Appropriate anti TNF $\alpha$ treatment can modify disease progression in axSpA as well as in nraxSpA $(34,35)$. Although not confirmed by all studies (14), in addition to TNF $\alpha$, the IL-23/IL-17 immune axis appears to be an important pathway in the pathogenesis of SpA and in DA (11-15, 36). IL-17 is the signature pro-inflammatory cytokine of a unique subset of T-helper cells, called Th17. Th17 cells differentiate from naïve $\mathrm{T}$ cells in a multistep process depending, first of all, on the presence of TGF- $\beta$, IL-6 and IL-1 inducing the expression of the Th17 master transcription factor called ROR-C. Another pro-inflammatory cytokine, IL-23 is crucial for stabilizing the Th17 phenotype and the expansion of Th17 populations. Other cells of both the adaptive and innate immune systems are activated by IL-23 and capable of producing IL-17 (11-15). These findings have led to defining the IL-23/IL-17 axis involved in mucosal and skin barrier function and in defense against germs, as well as playing a role in the pathogenesis of autoimmune and several inflammatory diseases, such as axSpA (37). The number of IL-17+T cells in peripheral blood is higher in AS patients with respect to that in healthy individuals $(12,37)$. Interestingly, the number of IL17 peripheral $\mathrm{T}$ cells is likewise higher in patients with early active axSpA both with and without MRI abnormalities (12).
IL-17 is up-regulated in facet joints (38) as well as in the blood circulation (39) of AS patients with respect to subjects with degenerative lesions or healthy controls. Although IL-23 serum levels (14, 40-42) and IL-23 expression in the subchondral bone marrow from the facet joints (26) are up-regulated in AS patients, no correlation has been found with MRI inflammation or clinical DA (24). As IL-17 and IL-23 levels fall significantly in responders to anti$\mathrm{TNF} \alpha$ drugs and rise in non-responders (41), both cytokines (IL-17, IL-23) are considered promising therapeutic targets $(42,43)$. In addition, IL-22 interconnected with IL-17 and Th17 cells is elevated in patients with AS (43). When IL-17, IL-22 and IL-23 were examined in our patients, they were found to be below detection levels in all three patient cohorts. The absence of any significant differences in the serum biomarker concentrations of the patients studied can probably be explained, firstly, by the patients' early disease stage (inflammatory low back pain $\geq 3$ months and $<2$ years) and, secondly, by the small sizes of the subgroups. In fact, the low number of patients studied should be considered the study's major limit. We would also underline that, in accordance with ASAS criteria, the inclusion criteria of patients for this study were primarily the presence of inflammatory LBP and clinical/immunogenetic and imaging SpA features, and only later the three cohorts were the three cohorts classified in accordance with the imaging data features (presence or absence of SIJ involvement in MRI and X-Rays and of spine involvement in MRI). We can also hypothesize al posto di we could also conjecture that the absence of elevated serum levels of inflammatory markers such as CRP and ESR could be explained by the fact that the inflammation was restricted to specific tissue compartments and did not extend to the systemic circulation and/or lymphoid organs in axSpA. In fact, other studies have reported that the immunopathology of tissues and inflammatory alterations are not always reflected in the peripheral blood compartment $(44,45)$. The findings outlined here are similar to those 
reported by another study (46) that did not uncover any differences in some biomarker levels in patients with early axSpA versus control back pain patients. In our population, there were no significant correlations between IL-17 and 23 levels and other serological, clinical and DA indices. Those biomarkers appeared to reflect early disease stages as opposed to IL-22 levels, which were correlated with some clinical indices, such as BASFI, BASG1, HAQ, VAS pain. High IL-22 expression and its correlation with other clinical and DA indices together with peripheral synovitis and diffuse skin psoriasis $(47,48)$ have been reported in patients with other forms of SpA, such as PsA (49). No significant correlations were instead found between skin involvement and serum levels of IL22 in those of our patients who had only minor skin involvement or onicopathy with PASI $<1$. Higher IL-22 levels even in the axial form of $\mathrm{SpA}$ could suggest that it plays a role in active sacroiliitis. In accordance with some published reports, a significant correlation between inter- and intra- clinical and DA indices and between ESR and hs-CRP was also noted $(16,17$, 47). The correlation between serological MMP3 levels and mSASSS, indicative of the role of metalloproteinases in the bone formation process, was an interesting finding and in accordance with data outlined by Maksymowych et al. (47) who reported that independently of other indices, serum MMP3 levels were able to predict two-year radiographic progression in the 97 axSpA patients studied. Our data also showed that MMP3 is correlated with inflammatory markers (hs-CRP and ESR) and, in agreement with previous studies, it is increased in the serum of patients with active axSpA $(24,26,27,47)$. The correlations between mSASS values and serum biomarkers require further evaluation by prospective studies. Some authors have reported a correlation between serum MMP3 levels and functional and DA indices (BASFI and BASDAI) $(27,47)$. It has been shown that MMP3 correlates with DA indices even in psoriatic arthritis (PsA) (49). As reported by Maksymowych et al., anti-TNF treat- ment induces a significant decrease in serum MMP3 levels as well as in ESR and BASDAI (47). Van Kuijk et al. (50) found that 24 patients randomized to receive 40 $\mathrm{mg}$ of adalimumab or placebo every 14 days showed a reduction in serum MMP3 levels after only 4 weeks after initiation of anti-TNF $\alpha$ therapy. No change was observed in the serum levels of the placebo group. Supporting the hypothesis that MMP3 could represent a reliable DA marker, the molecule was elevated in the patients with active SpA forms or in cases presenting severe clinical involvement.

\section{CONCLUSIONS}

Significant differences in clinical severity, DA indices, and biomarker levels were not found in the three cohorts of patients diagnosed with early axSpA and presenting different types of axial involvement (presence or absence of radiographic sacroiliitis and of active sacroiliitis on pelvic MRI) studied. ILs, MMP3 and hs-CRP values were not significantly higher in any of the cohorts and were not correlated to radiographic SIJ involvement. A significant correlation between IL-22 and some DA indices and between MMP3 and hsCRP was instead noted. The importance of diagnosing and treating axSpA early has been highlighted by numerous studies. Although the utility of some genetic and serological markers in diagnosing AS and $\operatorname{axSpA}$, monitoring DA, and predicting patients at risk of poor outcome has been investigated by many researchers, ESR and CRP continue to prove inadequate in monitoring SpA activity (46). The data outlined here suggest that peripheral blood compartment alterations do not reflect disease processes driving axial spondyloarthritis. As pointed out, the study's major limit is linked to the small numbers of patients studied and to the early disease stage (low back pain $\geq 3$ months, $\leq 2$ years, onset $<45$ years). Further studies are, of course, required to assess the validity and reproducibility of the DA biomarkers considered here in identifying and monitoring early stages of axSpA. 
Contributions: ML, manuscript drafting, data analyzing, acquiring and interpreting; RR, LP, study conceiving and design, data processing and manuscript drafting; SV, CLC, spine and pelvis X-rays and MRI images acquisition and interpretation; FO, statistical analysis, data analyzing and interpreting; MZ, CC, laboratory testing; $\mathrm{MF}, \mathrm{AO}$, data acquiring. All the authors have made substantial intellectual contributions to the study, have reviewed the manuscript, and have approved the version being submitted.

Acknowledgments: the authors wish to thank Linda Inverso for her assistance in editing the English version.

Conflicts of interest: None declared

\section{REFERENCES}

1. Rudwaleit M, van der Heijde D, Landewé $\mathrm{R}$, et al. The development of Assessment of Spondyloarthritis international Society classification criteria for axial spondyloarthritis (part II): validation and final selection. Ann Rheum Dis. 2009; 68: 777-83.

2. Braun J, van den Berg R, Baraliakos $X$, et al. 2010 update of the ASAS/EULAR recommendations for the management of ankylosing spondylitis. Ann Rheum Dis. 2011; 70: 896-904.

3. Ez-Zaitouni Z, Bakker PA, van Lunteren M, et al. Presence of multiple spondyloarthritis (SpA) features is important but not sufficient for a diagnosis of axial spondyloarthritis: data from the SPondyloArthritis Caught Early (SPACE) cohort. Ann Rheum Dis. 2017 [Epub ahead of print].

4. Van der Linden S, Valkenburg HA, Cats A. Evaluation of diagnostic criteria for ankylosing spondylitis. A proposal for modification of the New York criteria. Arthritis Rheum. 1984; 27: 361-8.

5. Rudwaleit M, Jurik AG, Hermann KG, et al. Defining active sacroiliitis on magnetic resonance imaging (MRI) for classification of axial spondyloarthritis: a consensual approach by the ASAS/OMERACT MRI group. Ann Rheum Dis. 2009; 68: 1520-7.

6. Hermann KG, Baraliakos X, van der Heijde DM, et al. Assessment in SpondyloArthritis international Society (ASAS). Descriptions of spinal MRI lesions and definition of a positive MRI of the spine in axial spondyloarthritis: a consensual approach by the ASAS/OMERACT MRI study group. Ann Rheum Dis. 2012; 71: 1278-88.
7. Robinson PC, Benham H. Advances in classification, basic mechanisms and clinical science in ankylosing spondylitis and axial spondyloarthritis. Intern Med J. 2015; 45: 127-33.

8. Prajzlerová K, Grobelná K, Pavelka K, et al. An update on biomarkers in axial spondyloarthritis. Autoimmun Rev. 2016; 15: 501-9.

9. Mohan C, Assassi S. Biomarkers in rheumatic diseases: how can they facilitate diagnosis and assessment of disease activity? BMJ. 2015; 351: h5079.

10. Bal A, Unlu E, Bahar G, et al. Comparison of serum IL-1 beta, sIL-2R, IL-6, and TNF-alpha levels with disease activity parameters in ankylosing spondylitis. Clin Rheumatol. 2007; 26: $211-5$.

11. Sherlock JP, Joyce-Shaikh B, Turner SP, et al. IL-23 induces spondyloarthropathy by acting on ROR-gammat+ CD3+CD4-CD8- entheseal resident T cells. Nat Med. 2012; 18: 1069-76.

12. Jansen DT, Hameetman M, van Bergen J, et al. IL-17- producing CD4+ T cells are increased in early, active axial spondyloarthitis including patients without imaging abnormalities. Rheumatology (Oxford). 2015; 54: 728-35.

13. Raychaudhuri SK, Saxena A, Raychaudhuri SP. Role of IL-17 in the pathogenesis of psoriatic arthritis and axial spondyloarthritis. Clin Rheumatol. 2015; 34: 1019-23.

14. Mei Y, Pan F, Gao J, et al. Increased serum IL-17 and IL-23 in the patient with ankylosing spondylitis. Clin Rheumatol. 2011; 30: 26973.

15. Duvallet E, Semerano L, Assier E, et al. Interleukin-23: a key cytokine in inflammatory diseases. Ann Med. 2011; 43: 503-11.

16. Pedersen SJ, Sørensen IJ, Garnero P, et al. ASDAS, BASDAI and different treatment responses and their relation to biomarkers of inflammation, cartilage and bone turnover in patients with axial spondyloarthritis treated with TNF $\alpha$ inhibitors. Ann Rheum Dis. 2011; 70: 1375-81.

17. Pedersen SJ, Sørensen IJ, Lambert RG, et al. Radiographic progression is associated with resolution of systemic inflammation in patients with axial spondylarthritis treated with tumor necrosis factor $\alpha$ inhibitors: a study of radiographic progression, inflammation on magnetic resonance imaging, and circulating biomarkers of inflammation, angiogenesis, and cartilage and bone turnover. Arthritis Rheum. 2011; 63: 3789-800.

18. De Vries MK, van Eijk IC, van der HorstBruinsma IE, et al. Erythrocyte sedimentation rate, C-reactive protein level, and serum amyloid a protein for patient selection and monitoring of anti-tumor necrosis factor treatment in ankylosing spondylitis. Arthritis Rheum. 2009; 61: 1484-90.

19. Poddubnyy DA, Rudwaleit M, Listing J, et al. Comparison of a high sensitivity and standard 
$\mathrm{C}$ reactive protein measurement in patients with ankylosing spondylitis and non-radiographic axial spondyloarthritis. Ann Rheum Dis. 2010; 69: 1338-41.

20. Visvanathan S, Wagner C, Marini JC, et al. Inflammatory biomarkers, disease activity and spinal disease measures in patients with ankylosing spondylitis after treatment with infliximab. Ann Rheum Dis. 2008; 67: 511-7.

21. Kiltz U, Baraliakos X, Karakostas P, et al. Do patients with non-radiographic axial spondylarthritis differ from patients with ankylosing spondylitis? Arthritis Care Res (Hoboken). 2012; 64: 1415-22.

22. Poddubnyy DA, Brandt H, Vahldiek J, et al. The frequency of non-radiographic axial spondyloarthritis in relation to symptom duration in patients referred because of chronic back pain: results from the Berlin early spondyloarthritis clinic. Ann Rheum Dis. 2012; 71: 1998 2001.

23. Poddubnyy D, Haibel H, Listing J, et al. Baseline radiographic damage, elevated acutephase reactant levels, and cigarette smoking status predict spinal radiographic progression in early axial spondylarthritis. Arthritis Rheum. 2012; 64: 1388-98.

24. Chen CH, Lin KC, Yu DT, et al. Serum matrix metalloproteinases and tissue inhibitors of metalloproteinases in ankylosing spondylitis: MMP-3 is a reproducibly sensitive and specific biomarker of disease activity. Rheumatology (Oxford). 2006; 45: 414-20.

25. Yang C, Gu J, Rihl M, et al. Serum levels of matrix metalloproteinase 3 and macrophage colony-stimulating factor 1 correlate with disease activity in ankylosing spondylitis. Arthritis Rheum. 2004; 51: 691-9.

26. Soliman E, Labib W, el-Tantawi G, et al. Role of matrix metalloproteinase-3 (MMP-3) and magnetic resonance imaging of sacroiliitis in assessing disease activity in ankylosing spondylitis. Rheumatol Int. 2012; 32: 1711-20.

27. Maksymowych WP, Landewé R, ConnerSpady B, et al. Serum matrix metalloproteinase 3 is an independent predictor of structural damage progression in patients with ankylosing spondylitis. Arthritis Rheum. 2007; 56: 1846-53.

28. Hermann KG, Baraliakos X, van der Heijde DM, et al. Assessment in SpondyloArthritis international Society (ASAS). Descriptions of spinal MRI lesions and definition of a positive MRI of the spine in axial spondyloarthritis: a consensual approach by the ASAS/OMERACT MRI study group. Ann Rheum Dis. 2012; 71: 1278-8.

29. Lorenzin M, Ortolan A, Frallonardo P, et al. Spine and sacroiliac joints on magnetic resonance imaging in patients with early axial spondyloarthritis: prevalence of lesions and association with clinical and disease activity indices from the Italian group of the SPACE study. Reumatismo. 2016; 68: 72-82.

30. Maksymowych WP, Inman RD, Salonen D, et al. Spondyloarthritis Research Consortium of Canada magnetic resonance imaging index for assessment of sacroiliac joint inflammation in ankylosing spondylitis. Arthritis Rheum. 2005; 53: 703-9.

31. Maksymowych WP, Inman RD, Salonen D, et al. Spondyloarthritis Research Consortium of Canada magnetic resonance imaging index for assessment of spinal inflammation in ankylosing spondylitis. Arthritis Rheum. 2005; 53: 502-9.

32. Creemers MC, Franssen MJ, van't Hof MA, et al. Assessment of outcome in ankylosing spondylitis: an extended radiographic scoring system. Ann Rheum Dis. 2005; 64: 127-9.

33. Braun J, Baraliakos X, Heldmann F, Kiltz U. Tumor necrosis factor alpha antagonists in the treatment of axial spondyloarthritis. Exp Opin Investig Drugs. 2014; 23: 647-59.

34. Ciprian L, Lo Nigro A, Rizzo M, et al. The effects of combined spa therapy and rehabilitation on patients with ankylosing spondylitis being treated with TNF inhibitors. Rheumatol Int. 2013; 33: 241-5.

35. Lubrano E, Perrotta FM, Marchesoni A, et al. Remission in nonradiographic axial spondyloarthritis treated with anti-tumor necrosis factor- $\alpha$ drugs: an Italian multicenter study. J Rheumatol. 2015; 42: 258-63.

36. Reveille JD. Biomarkers for diagnosis, monitoring of progression, and treatment responses in ankylosing spondylitis and axial spondyloarthritis. Clin Rheumatol. 2015; 34: 1009-18.

37. Shen H, Goodall JC, Hill Gaston JS. Frequency and phenotype of peripheral blood Th17 cells in ankylosing spondylitis and rheumatoid arthritis. Arthritis Rheum. 2009; 60: 1647-56.

38. Appel H, Maier R, Wu P, et al. Analysis of IL-17(+) cells in facet joints of patients with spondyloarthritis suggests that the innate immune pathway might be of greater relevance than the Th17-mediated adaptive immune response. Arthritis Res Ther. 2011; 13: R95.

39. Xueyi L, Lina C, Zhenbiao W, et al. Levels of circulating Th17 cells and regulatory $\mathrm{T}$ cells in ankylosing spondylitis patients with an inadequate response to anti-TNF- $\alpha$ therapy. J Clin Immunol. 2013; 33: 151-61.

40. Wang X, Lin Z, Wei Q, et al. Expression of IL23 and IL-17 and effect of IL-23 on IL-17 production in ankylosing spondylitis. Rheumatol Int. 2009; 29: 1343-7.

41. Andersen T, Rasmussen TK, Hvid M, et al. Increased plasma levels of IL-21 and IL-23 in spondyloarthritis are not associated with clinical and MRI findings. Rheumatol Int. 2012; 32: 387-93.

42. Poddubnyy D, Hermann KG, Callhoff J, et al. Ustekinumab for the treatment of patients 
with active ankylosing spondylitis: results of a 28-week, prospective, open-label, proofof-concept study (TOPAS). Ann Rheum Dis. 2014; 73: 817-23.

43. Appel H, Maier R, Bleil J, et al. In situ analysis of interleukin-23- and interleukin-12-positive cells in the spine of patients with ankylosing spondylitis. Arthritis Rheum. 2013; 65: 1522-9.

44. Noordenbos T, Yeremenko N, Gofita I, et al. Interleukin-17-positive mast cells contribute to synovial inflammation in spondylarthritis. Arthritis Rheum. 2012; 64: 99-109.

45. Yeremenko N, Noordenbos T, Cantaert T, et al. Disease-specific and inflammation-independent stromal alterations in spondylarthritis synovitis. Arthritis Rheum. 2013; 65: 174-85.

46. Turina MC, Yeremenko N, van Gaalen F, et al. Serum inflammatory biomarkers fail to identify early axial spondyloarthritis: results from the SpondyloArthritis Caught Early (SPACE) cohort. RMD Open. 2017; 3: e000319.
47. Maksymowych WP, Fitzgerald O, Wells GA, et al. Proposal for levels of evidence schema for validation of a soluble biomarker reflecting damage endpoints in rheumatoid arthritis, psoriatic arthritis, and ankylosing spondylitis, and recommendations for study design. J Rheumatol. $2009 ; 36$ : 1792-9.

48. Fiocco U, Sfriso P, Oliviero F, et al. Synovial effusion and synovial fluid biomarkers in psoriatic arthritis to assess intraarticular tumor necrosis factor- $\alpha$ blockade in the knee joint. Arthritis Res Ther. 2010; 12: R148.

49. Ramonda R, Modesti V, Ortolan A, et al. Serological markers in psoriatic arthritis: promising tools. Exp Biol Med (Maywood). 2013; 238: 1431-6.

50. van Kuijk AW, DeGroot J, Koeman RC, et al. Soluble biomarkers of cartilage and bone metabolism in early proof of concept trials in psoriasic arthritis: effects of adalimumab versus placebo. PLoS One. 2010; 5: e12556. 